\title{
The effective application of mud cooler machine to operate the infill wells in Cuu Long basin
}

\author{
Tuan Tran Nguyen $1{ }^{1}$, , Son Hoang Nguyen ${ }^{2}$ \\ ${ }^{1}$ Hanoi University of Mining and Geology, Hanoi, Vietnam \\ 2 An Phong Insulation Company, Hanoi, Vietnam
}

\section{ARTICLE INFO}

Article history:

Received 02 ${ }^{\text {nd }}$ Feb. 2021

Revised 21 $1^{\text {st }}$ May 2021

Accepted 15 $5^{\text {th }}$ June 2021

\section{Keywords:}

Cuu Long basin,

High temperature,

High pressure.

\section{ABSTRACT}

This paper presents some studies on the application of mud cooler in Oil \& Gas drilling in a high temperature, high pressure condition of Cuu Long reservoir. The authors have proposed a method to study the theory of temperature effects on drilling fluid properties, that have been tested practically. The authors have remarked on each type of drilling rig and installation location. With these remarks, the authors give an option to install the "Mud cooler" on the rig at the appropriate location and method so that the temperature of the solution will be ensured to reduce to a safe level. The effective application of this equipment has greatly assisted drilling process since the fluid temperature has been reduced sharply before returning to the mud tank. This has helped cut down expenses significantly by prolonging eqipment's endurability, saving time for drilling, ship renting, drilling services and minimize the budget spent on buying the fluid and additives to recover it. Thus, the drilling workers' working conditions have been facilitated. The results of these studies have been proved scientifically and practically through the successful drilling of well ST-3P-ST. This will make the way for other local wells and reservoirs which have the same conditions of temperature and pressure.

${ }^{*}$ Corresponding author

E - mail: nguyentrantuan1102@gmail.com

DOI: 10.46326/JMES.2021.62(3a).09 


\title{
Tạp chí Khoa học Kỹ thuật Mỏ - Địa chất
}

Trang điện tử: http://tapchi.humg.edu.vn

\section{Nghiên cứu nâng cao hiệu quả thiết bị làm mát dung dịch để thi công các giếng đan dày ở bể Cửu Long}

\author{
Nguyễn Trần Tuan ${ }^{1,}{ }^{*}$, Nguyễn Hoàng Sơn ${ }^{2}$ \\ ${ }^{1}$ Trường Đại học Mỏ-Địa chất, Hà Nội , Việt Nam \\ 2 Công Ty Cách Nhiệt An Phong, Hà Nội, Việt Nam
}

\begin{abstract}
THÔNG TIN BÀI BÁO T TÓM TẮT
Quá trình:

Nhận bài 02/02/2021

Sửa xong $21 / 5 / 2021$

Chấp nhận đăng 15/6/2021

Tù khóa:

Áp suất cao,

Bể Cửu Long,

Nhiệt độ cao.

Bài báo trình bày một số kết quả nghiên cứu úng dụng thiết bị làm mát dung dịch trong công tác khoan dầu khí để thi công các giếng đan dày trong điều kiện nhiệt độ và áp suất cao ở bể Cưu Long. Bằng phương pháp nghiên cúu lý thuyết và thư nghiệm thực tế về sự ảnh hương của nhiệt độ tới tính chất của dung dịch khoan. Tác giả đã phẩn tích đặc tính kỹ thuật tùng loại giàn khoan và đề xuất phương án lắp đặt thiết bị "Mud cooler" phù hợ để đảm bảo nhiệt độ của dung dịch giảm tới mức an toàn. Ứng dụng thiết bi "Mud cooler" đã đem lại nhũng hiệu quả trong việc thi công các giếng khoan do nhiệt độ của dung dịch được giảm mạnh trước khi hồi về bể chứa, góp phần tăng tuổi thọ thiết bị, giảm thời gian khoan, thời gian thuê tàu, thuê dịch vu khoan và giảm thiểu chi phí sử dụng chất phụ gia để gia công và phục hồi tính chất của dung dịch khoan; cải thiện điều kiện làm việc cho người thợ khoan. Kết quả nghiên cưu đã áp dụng thử nghiệm thành công tại giếng khoan ST-3P-ST ở bể Cưu Long. Kết quảnghiên cúu lý thuyết và thự nghiệm sẽ là tiền đề mở rộng cho việc thi công các giếng khoan dầu khí có điều kiện nhiệt độ và áp suất tương tự.
\end{abstract}

C 2021 Trường Đại học Mỏ - Địa chất. Tất cả các quyền được bảo đảm.

\section{Mở đầu}

Hiện nay, mỏ Sư Tử Trắng thuộc bể Cửu Long đang thi công các giếng khoan đan dày nhằm tìm kiếm và nâng cấp trữ lượng dầu và khí. Các giếng khoan đan dày ở mỏ Sư Tử Trắng đều là giếng nhiệt độ và áp suất cao. Trong giếng nhiệt độ và áp suất cao (HPHT), ngay cả dung dịch khoan chịu nhiệt tốt nhất cũng chỉ có giới hạn nhất định. Nếu vượt quá nhiệt độ và áp suất giới hạn, dung dịch khoan bị phá vỡ cấu trúc, mất tính ổn định làm thay đổi các thông số như giảm độ nhớt, độ thải nước,... dẫn đến các phức tạp và sự cố trong khoan. Kết quả nghiên cứu lý thuyết và thực tế cho thấy ở nhiệt độ trên $80^{\circ} \mathrm{C}$ độ nhớt của hầu hết các loại

*Tác giả liên hệ

E - mail: nguyentrantuan1102@gmail.com

DOI: 10.46326/JMES.2021.62(3a).09 
dung dịch khoan chỉ còn 0,35 cp; điều này ảnh hưởng nghiêm trọng tới cấu trúc của dung dịch (Trần Đình Kiên, 2002); gây ra sự mất ổn định thành giếng (Trương Biên và nnk., 2007) và các sự cố phức tạp trong khoan, đòi hỏi chi phí nhiều thời gian thi công giếng và chi phí các hóa phẩm để gia công dung dịch, dẫn tới giá thành khoan giếng tăng. Đồng thời, khi nhiệt độ dung dịch khoan tăng quá nhiệt độ cho phép sẽ ảnh hưởng đến khả năng làm việc và tuổi thọ của thiết bị khoan, đến khả năng làm việc của bộ dụng cụ khoan; tới mức độ chính xác của thiết bị đo lường (MWD) và các thiết bị ghi (LWD) trong khi khoan. Chúng cũng có thể dẫn đến sự hao mòn quá mức các chi tiết đàn hồi của các thiết bị đo MWD, LWD; làm hư hỏng vòng bịt kín bằng cao su của thiết bị chống phun (BOP), của máy khuấy, máy ly tâm và máy bơm dung dịch (Trần Đình Kiên, 2002; Trương Biên và nnk., 2007).

Ngoài ra, dung dịch khoan quá nóng có thể giải phóng khí và hơi độc từ các hóa phẩm gia công trong dung dịch, gây ô nhiễm và nguy hiểm đến môi trường làm việc của người thợ khoan.

Phân tích các tài liệu địa chất và chế độ nhiệt trong các giếng khoan ở bể Cửu Long, tác giả nhận thấy việc sử dụng các phương tiện "Mud cooler" đểlàm mát hoặc giữ ổn định nhiệt độ cho phép của dung dịch khoan trong hệ tuần hoàn giếng là việc không thể thiếu, có tính cần thiết đáp ứng kịp thời yêu cầu sản xuất và giảm thiểu những tác động không tốt của nhiệt độ trong giếng khoan.

\section{Chế độ và phân bố nhiệt trong giếng khoan}

Trong quá trình khoan, dung dịch khoan bị làm nóng bởi nhiều yếu tố kết hợp với nhau như sự kết hợp giữa áp suất, nhiệt độ tự nhiên trong thành hệ giếng với ma sát cơ học do bộ dụng cụ khoan làm việc. Điều này đã làm cho tính lưu biến của dung dịch thay đổi; đặc biệt độ nhớt của dung dịch sẽ giảm xuống dưới mức cho phép bởi khi đó chuyển động phân tử tăng lên (Hình 1), cấu trúc của dung dịch có thể bị phá vỡ, lực ma sát nội sẽ bị giảm. Hiện tượng này được giải thích bằng thuyết động học phân tử.

Để dịch chuyển tương đối giữa 2 lớp chất lỏng với nhau cần tác dụng một lực là $\mathrm{F}_{1}$ nào đó, lực này có giá trị bằng lực ma sát nội tỷ lệ thuận với diện tích bề mặt tiếp xúc $\mathrm{S}$ của lớp chất lỏng. Mối liên quan giữa lực tác dụng và diện tích tiếp xúc có thể biểu diễn bằng công thức:

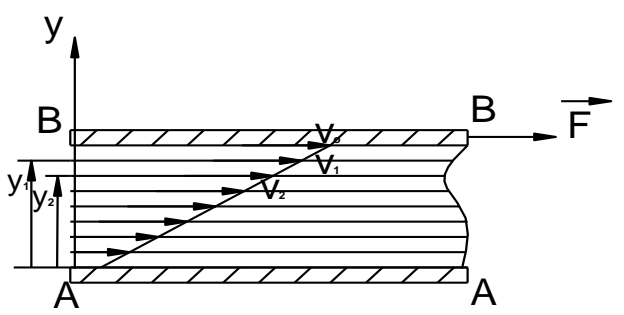

Hình 1.Chuyển động của các lớp chất lỏng.

$$
\mathrm{F}_{1}=\mathrm{fS}
$$

Trong đó: $\mathrm{f}$ - ứng suất trượt (đặt trên 1 đơn vị diện tích); $\mathrm{S}$ - diện tích 2 lớp tiếp xúc.

Vận tốc chuyển động của các lớp thay đổi theo quy luật tuyến tính, nghĩa là tỷ lệ với khoảng cách từ chúng tới mặt phẳng chuyển động $\mathrm{B}-\mathrm{B}$ theo công thức:

$$
\frac{V_{1}}{Y_{1}}=\frac{V_{2}}{Y_{2}}
$$

Ứng suất trượt f tỷ lệ với sự biến thiên vận tốc theo hướng của trục tung $(\mathrm{y})$ và phụ thuộc vào $(\mathrm{y})$ theo quy luật tuyến tính. Vì thế ta có thể viết:

$$
f=\eta \frac{V}{y}
$$

Trong đó: $\eta$ - hệ số ma sát nội phụ thuộc vào tính chất của chất lỏng, thay (3) vào (1) ta có:

$$
F_{1}=\eta S \frac{V}{y}
$$

Tổng quát hơn, ứng với sự thay đổi gradien vận tốc trên một chiều dày đủ nhỏ bất kỳ giữa 2 lớp chất lỏng, ta có:

$$
F=\eta \mathrm{S} \frac{d v}{d y}
$$

Từ đó ta có:

$$
\eta=\frac{F d y}{s d v}
$$

Về mặt ý nghĩa vật lý thì hệ số $\eta$ là lực tiếp tuyến cần thiết để làm dịch chuyển tương đối giữa hai lớp chất lỏng có bề mặt tiếp xúc là 1 đơn vị diện tích, cách nhau 1 đơn vị độ dài với vận tốc là 1 đơn vị vận tốc.

Trong quá trình tuần hoàn dung dịch, sự trao đổi nhiệt từ đáy giếng lên bề mặt được diễn ra trong suốt quá trình khoan. Biên độ chênh lệch nhiệt độ giữa đáy giếng và nóc vỉa phụ thuộc chủ yếu vào vận tốc chuyển động của dòng chảy dung dịch trong hệ tuần hoàn giếng khoan (Gilles và nnk., 2014).

Chế độ nhiệt trong suốt chiều dài thân giếng thay đổi hết sức phức tạp và phụ thuộc vào nhiều yếu tố. Graddien nhiệt độ trong các giếng khoan không giống nhau; giếng khoan càng sâu, nhiệt độ thân giếng càng lớn (Hình 2), càng làm thay đổi 


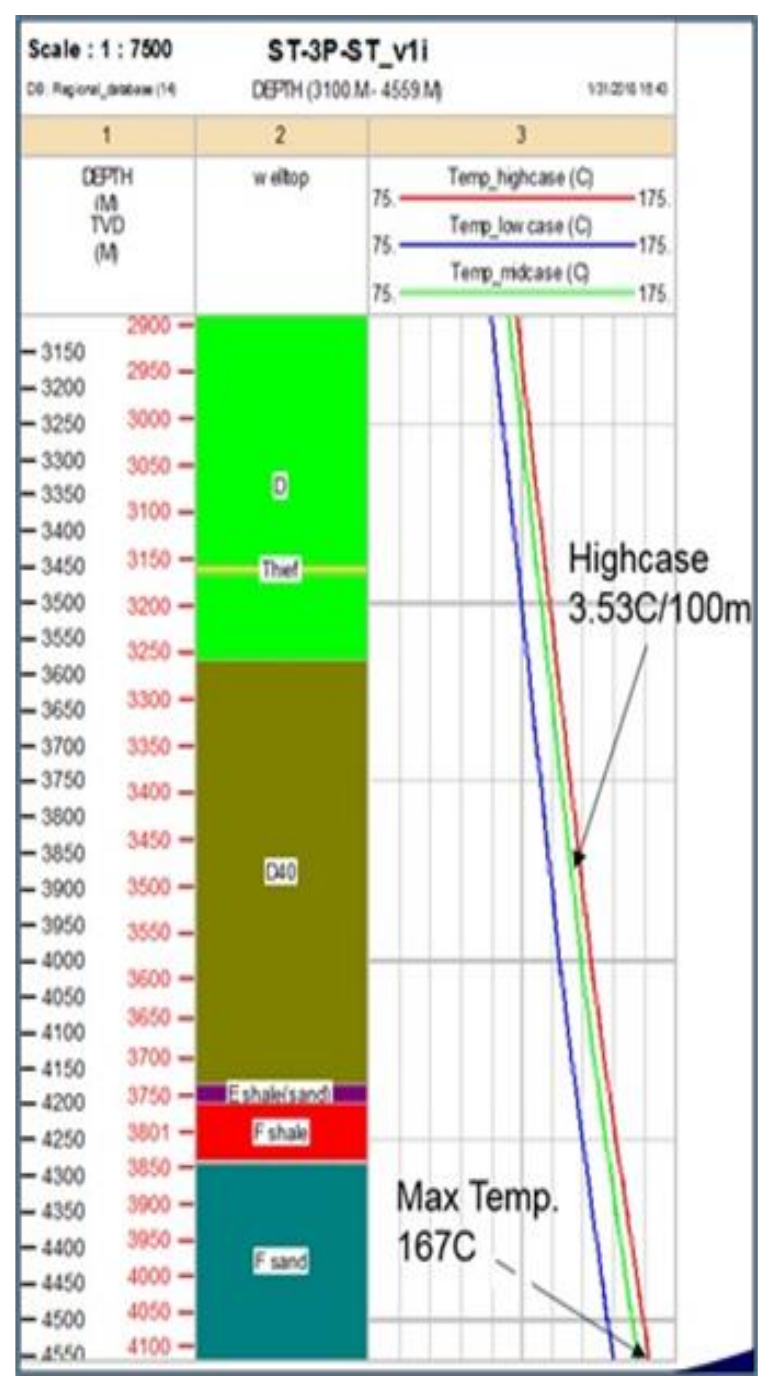

Hình 2. Đường biểu thị nhiệt độ của giếng ST3P-ST mỏ Sư Tư Trắng.

tính chất lưu biến của dung dịch. Ngày nay, phần mềm máy tính như MI-Swaco, Halliburton Baroid, Scomi,... dễ dàng cung cấp số liệu có tính chất định tính, chi tiết về cấu hình nhiệt độ trong giếng khoan; kết hợp với các kết quả thu được từ thiết bị đo MWD trong khi khoan, ta có thể nhận biết chính xác nhiệt độ đáy giếng để đề xuất các giải pháp xử lý phục hồi tính chất dung dịch khoan (Công ty liên doanh điều hành Cửu Long, 2018).

\section{Khảo sát lắp đặt thiết bị làm mát dung dịch khoan "Mud cooler" và kết quả thử nghiệm}

\subsection{Lắp đặt thiết bị làm mát dung dịch khoan "Mud cooler" trên giàn khoan giếng ST-3P-ST}

Trên cơ sở nghiên cứu nguyên lý làm việc của thiết bị "Mud cooler" và khảo sát thực tế, phân tích đặc thù từng loại giàn khoan và vị trí lắp đặt; thấy rằng nếu lắp đặt thiết bị làm mát dung dịch khoan "Mud Cooler"trên giàn tại vị trí không phù hợp thì "nhiệt độ của dung dịch sẽ không giảm tới mức an toàn để thi công". Nhiều thử nghiệm đã được thực hiện để kiểm tra tính thực tiễn của việc lắp đặt các hệ thống làm mát bằng dung dịch cho thấy: nếu lắp đặt thiết bị làm mát hợp lý, phù hợp với loại giàn khoan sẽ đem lại hiệu quả cao trong việc giảm nhiệt độ giếng, tăng tuổi thọ thiết bị khoan, kiểm soát tốt tính lưu biến dung dịch với ít sử dụng chất phụ gia, sử dụng hiệu quả các thiết bị MWD.

Ưu điểm của hệ thống thiết bị làm mát dung dịch khoan "Mud Cooler":

- Các bộ phận có thểhoạt động song song hoặc nối tiếp để phù hợp với hoạt động khoan; tỷ lệ lưu thông dung dịch và giảm nhiệt độ theo yêu cầu nhà thầu thi công;

- Theo dõi tình trạng hoạt động của thiết bị bằng đồng hồ đo áp suất và nhiệt kế cơ học của tất cả các dòng chảy qua thiết bị;

- Khung và khung trượt được cấp chứng chỉ nâng hạ cho thiết bị hoạt động ngoài biển;

- Đường chảy lớn để ngăn chặn tắc nghẽn trong quá trình thiết bị hoạt động;

- Thiết bị dễ sử dụng và lắp đặt dễ dàng trên giàn khoan thông qua các đầu kết nối ống nhanh;

- Tất cả các chi tiết của thiết bị được chế tạo theo tiêu chuẩn của Hiệp hội kỹ sư cơ khí Mỹ (ASME) và Viện dầu khí Mỹ (API);

- Thiết kế nhỏ gọn cho phép dễ dàng vận chuyển bằng xe tải trên bờ và tàu dịch vụ trên biển, hoặc bằng container và giảm thiểu yêu cầu không gian boong để lắp đặt thiết bị.

Ngay từ khi đưa giàn khoan vào vị trí khoan ở biển; thiết bị làm mát dung dịch khoan "Mud Cooler" được tiến hành lắp đặt song song với các thiết bị khoan khác. Khi khoan dòng dung dịch được tuần hoàn lên bề mặt chảy qua hệ thống thiết bị làm mát dung dịch khoan "Mud Cooler"trước khi chảy về hệ thống bể chứa. Với hoạt động hiệu quả của hệ thống làm mát, nhiệt độ dung dịch được giảm từ $10 \div 15^{\circ} \mathrm{C}$ giúp cho hệ thống máy bơm, dụng cụ khoan trong giếng, các thiết bị đo LWD/MWD đảm bảo hoạt động lâu dài hơn, giảm thời gian từ $1 \div 2$ ngày do phải kéo thả thay thế bộ dụng cụ khoan. Đặc biệt, với hệ thống làm mát dung dịch thì tính chất dung dịch được bảo đảm 
tốt hơn, không bị phá vỡ cấu trúc của dung dịch, và giảm giá thành dung dịch do không phải thêm nhiều hóa chất phụ gia để bổ sung cho tính chất dung dịch.

Có 2 phương pháp lắp đặt hệ thống thiết bị làm mát dung dịch khoan "Mud Cooler"trên giàn khoan: i) Phương pháp lắp đặt trực tiếp từ phòng máy bơm, đầu nối Mud Cooler được lắp trực tiếp vào bể chứa dung dịch và dòng hồi dung dịch đã được làm mát sẽ chảy trực tiếp trở lại vào chính bể chứa dung dịch (Hình 3). Ii) Phương pháp lắp đặt trên bề mặt; đầu nối Mud Cooler nối trực tiếp vào bể lắng cát ngay bên dưới sàng rung và dòng hồi dung dịch đã được làm mát sẽ chảy về đường hồi vào bể chứa dung dịch (Hình 4).

Sau khi khảo sát giàn khoan jack-up PVD6, hệ thống Mud Cooler được đề xuất lắp đặt như sau (Hình 5):

- Thiết bị làm mát dung dịch khoan "Mud Cooler"được lắp đặt tại mạn phải của giàn khoan, bên dưới sàn cantilever cạnh hệ thống máy bơm vữa xi măng. Trọng lượng cụm Mud Cooler 6,1 tấn; cần diện tích bề mặt lắp đặt $13 \mathrm{~m}^{2}$ (kích thước thiết bị dài 4,8 $\mathrm{m}$ x rộng 2,3 $\mathrm{m}$ x cao 2,05 m);

- Thiết bị lọc (Strainer) được lắp đặt cạnh mạn phải của giàn khoan; trọng lượng thiết bị Strainer 1 tấn; diện tích lắp đặt 2,1 $\mathrm{m}^{2}$ (kích thước thiết bị rộng $0,99 \mathrm{~m} x$ dài $2,12 \mathrm{~m}$ x cao $1,1 \mathrm{~m}$ );
- Máy bơm ly tâm (Centrifugal Pump) được lắp đặt tại mạn phải của giàn, ngay khu vực sàng rung;

- Máy bơm điện chìm (Submersible Pump) dự phòng để cung cấp nước biển làm mát thiết bị Mud Cooler trong trường hợp hệ thống bơm nước biển của giàn khoan bị hư hỏng.

\subsection{Kết quả thử nghiệm thiết bị làm mát dung dịch khoan "Mud cooler" tại giếng khoan ST-3P- ST}

Giếng khoan ST-3P-ST thuộc mỏ Sư Tử Trắng của Cửu Long JOC là giếng nhiệt độ và áp suất cao; nhiệt độ đáy giếng lên tới gần $170^{\circ} \mathrm{C}$ (Hình 1 ) (Công ty liên doanh điều hành Cửu Long, 2018).

Giếng khoan được thiết kế mở cửa sổ từ thân giếng cũ qua ống chống 131/8" tại chiều sâu 1.686 mMD. Khoan $121 / 4$ " và chống ống $95 / 8$ " tới chiều sâu 3.500 mMD/3.200 mTVD; sau đó khoan thân giếng đường kính 8 1/2" và chống ống lửng 7" từ 3.400 mMD tới 4.298 mMD; đoạn cuối của giếng được khoan đường kính 6" và chống ống lửng 4 $1 / 2$ " từ 4.098 mMD tới 4.562 mMD. Cấu trúc giếng khoan ST-3P-ST xem Hình 6 (Công ty liên doanh điều hành Cửu Long, 2018).

Giếng khoan ST-3P-ST được thiết kế sử dụng hệ dung dịch khoan gốc dầu (SBM), với tính ức chế sét rất tốt. Nhưng do nhiệt độ trong giếng khoan cao, cấu trúc và tính lưu biến của dung dịch luôn

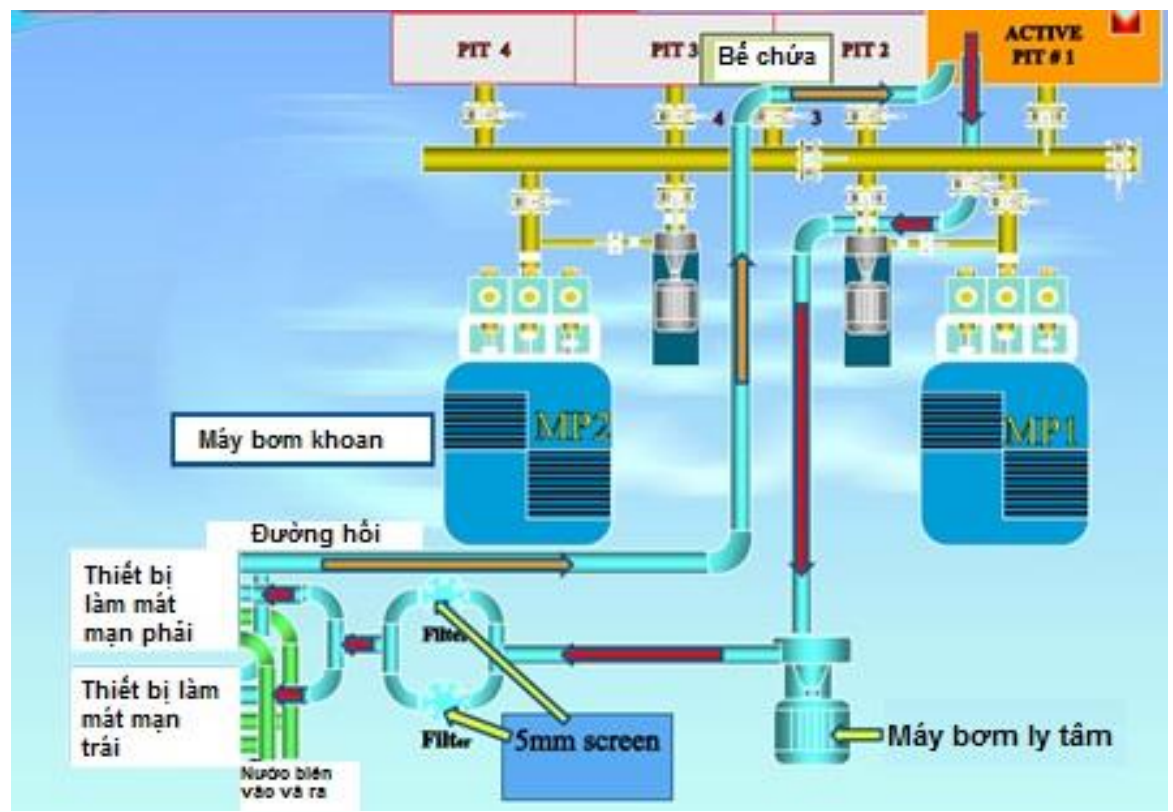

Hình 3. Sơ đồ lắp đặt hệ thống Mud Cooler trên giàn khoan (tù̀ phòng máy bơm). 


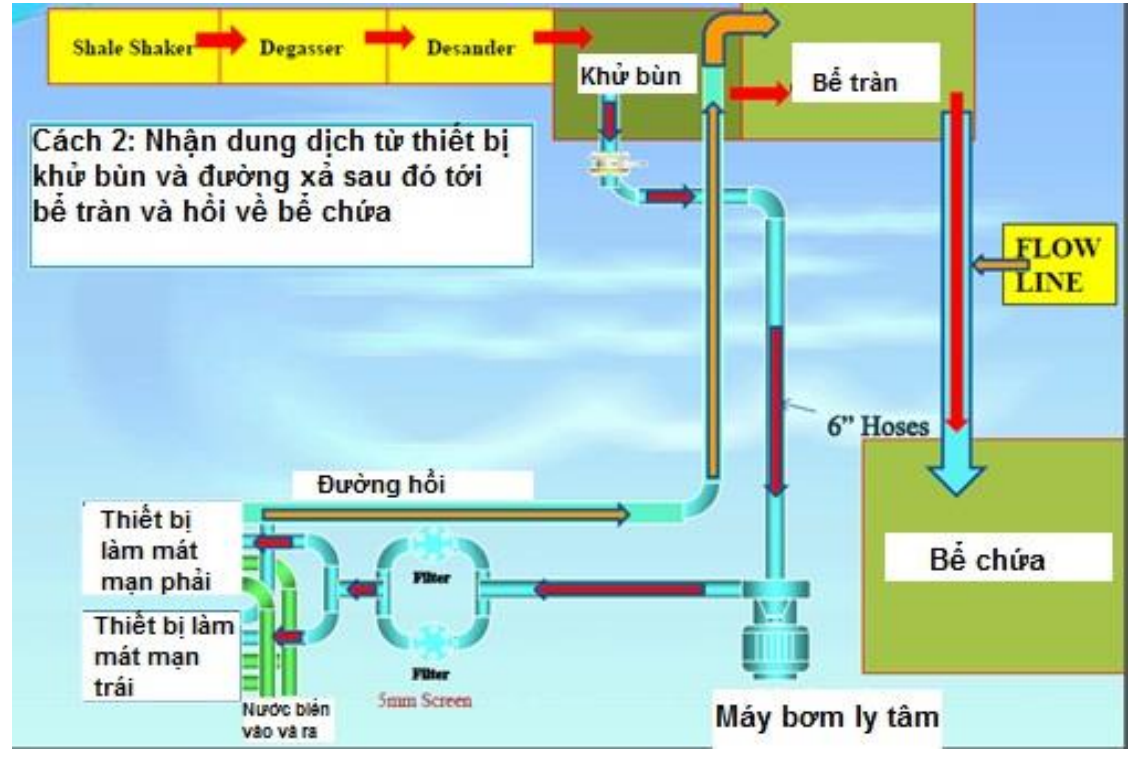

Hình 4. Sơ đồ lắp đặt hệ thống Mud Cooler trên giàn khoan (trực tiếp vào bể lắng).

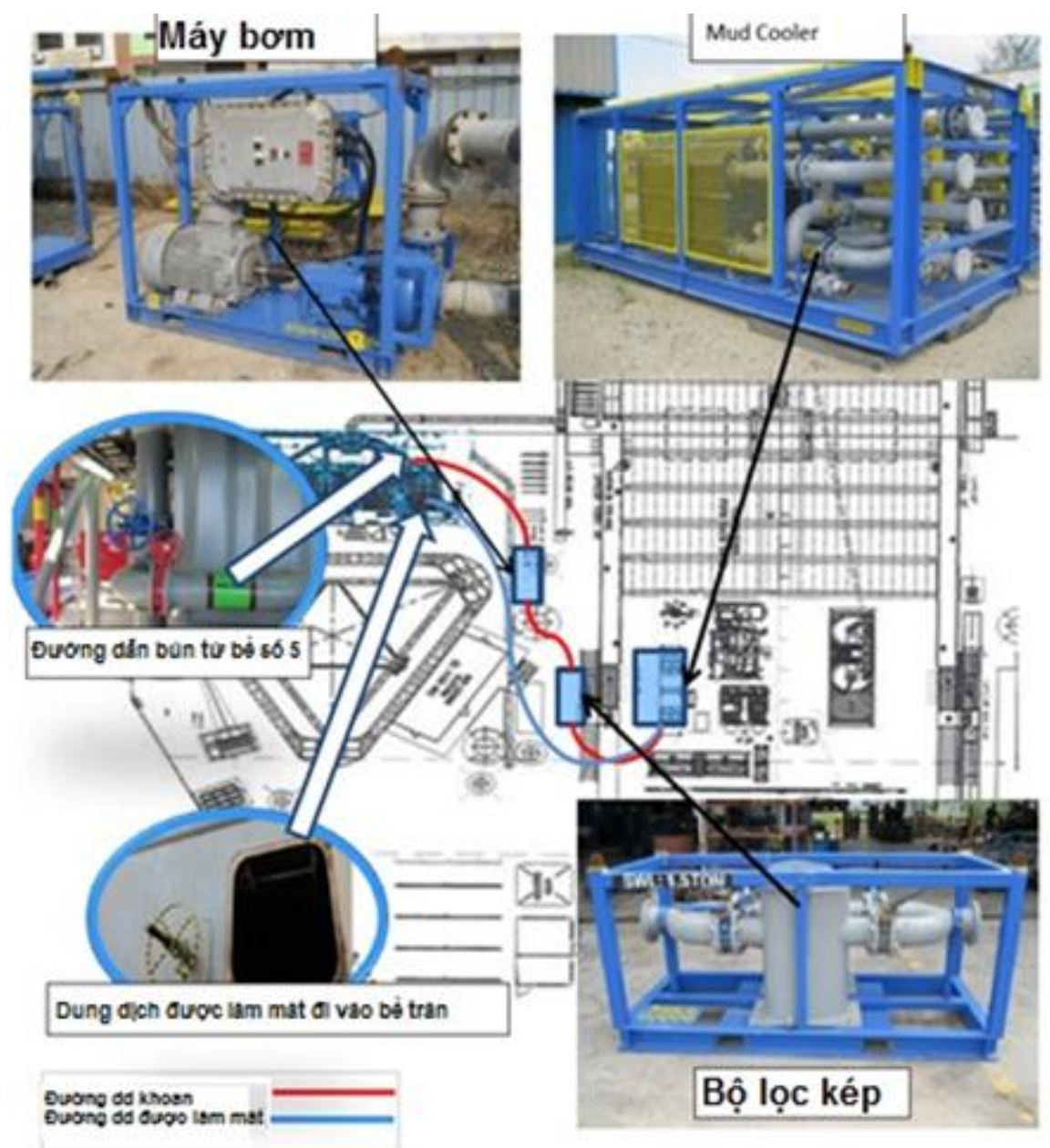

Hình 5. So đồ lắp đặt Mud Cooler trên giàn khoan jack-up PVD6. 


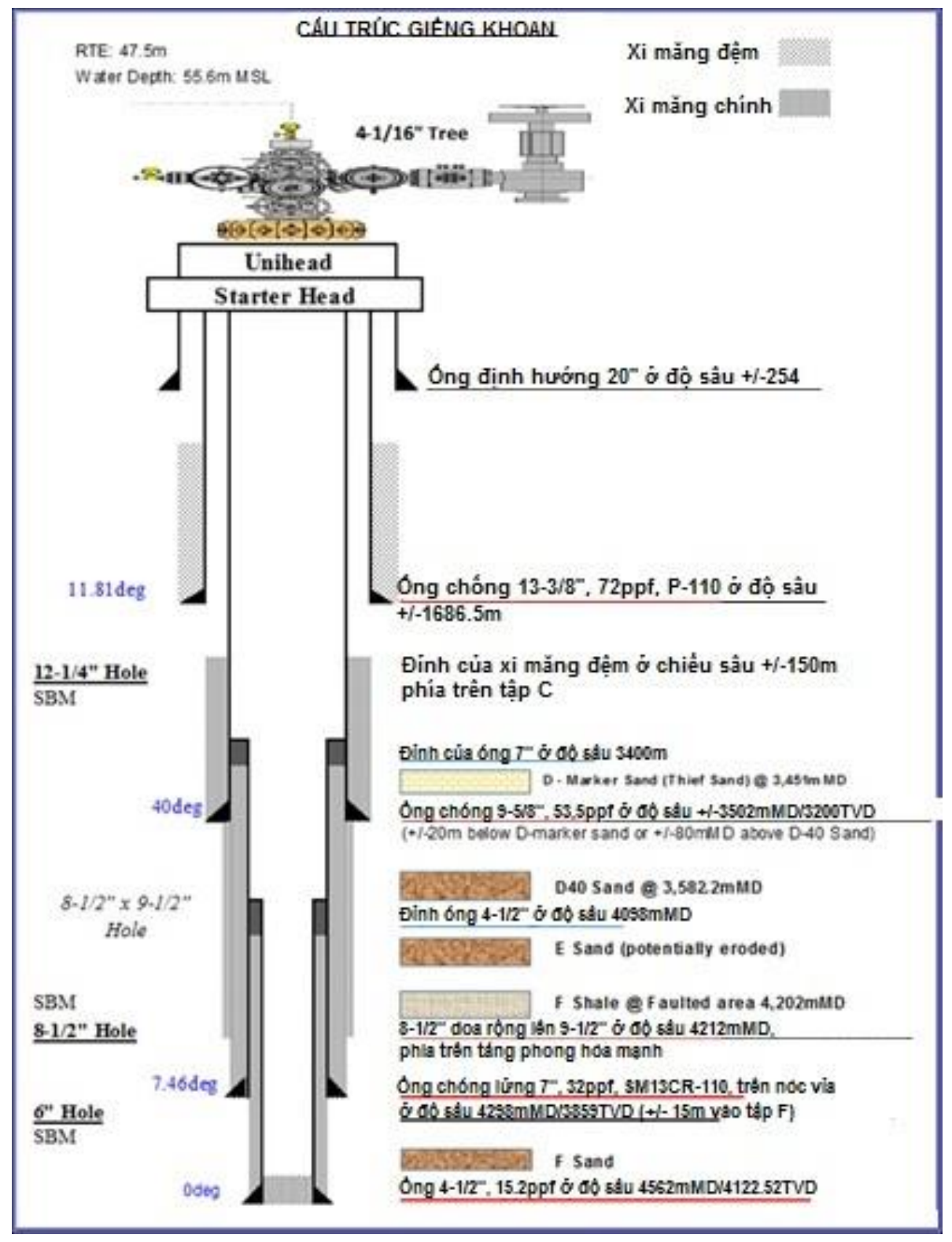

Hình 6. Cấu trúc giếng ST-3P-ST.

thay đổi làm ảnh hưởng tới sự ổn định thành giếng khoan. Hơn nữa, đây là giếng sử dụng hệ dung dịch khoan gốc dầu cần phải duy trì ở nhiệt độ dưới nhiệt độ tự bốc cháy của bọt dầu để đảm bảo điều kiện an toàn của công tác khoan.

Chính vì vậy, Công ty dầu khí Cửu Long đã quyết định sử dụng thử nghiệm hệ thống làm mát dung dịch "Mud cooler" cho giếng ST-3P-ST.

Kết quả thử nghiệm cho thấy: nhiệt độ của giếng khoan càng cao thì hiệu quả giảm nhiệt độ của dung dịch khi đi qua hệ thống Mud cooler càng rõ ràng (Công ty liên doanh điều hành Cửu Long, 2018). Với kết quả nhiệt độ giảm Min-Mid-Max là: $10^{\circ} \mathrm{C}-17^{\circ} \mathrm{C}-20^{\circ} \mathrm{C}$ đã chứng minh hiệu quả ứng dụng hệ thống làm mát dung dịch để hỗ trợ cho các giếng khoan nhiệt độ và áp suất cao (HPHT). Các kết quả thử nghiệm thiết bị làm mát Mud cooler ở giếng khoan ST-3P-ST được trình bày ở Bảng 1 . Từ các kết quả đạt được do ứng dụng thiết bị làm mát ở giếng ST-3P-ST; nghiên cứu đã tính toán tiết kiệm chi phí cho công tác khoan từ nghiên cứu ứng dụng này. Nếu giảm 1 lần kéo thả sẽ tiết kiệm được 2 ngày làm việc của giàn khoan, từ đó sẽ giảm đáng kể giá thành khoan. Kết quả tính toán chi phí xem Bảng 2. 
Bảng 1. Các kết quả sử dụng hệ thống làm mát dung dịch "Mud cooler" tại giếng khoan ST-3P-ST.

\begin{tabular}{|c|c|c|c|c|c|c|c|c|c|c|c|c|}
\hline Chläu sdu khoan & 3075 & 3099 & 3118 & 3149 & 3175 & 3195 & 3234 & 3260 & 3292 & 3331 & 3360 & 3373 \\
\hline \multicolumn{6}{|l|}{ Parameter } & \multicolumn{7}{|c|}{$\square \cdot \mathbf{F}$} \\
\hline Dung dich vaso & 63 & 64 & 62 & 63 & 65 & 65 & 63 & 62 & 62 & 64 & 64 & 64 \\
\hline Dung dich ra & 53 & 54 & 53 & 53 & 54 & 54 & 54 & 53 & 53 & 54 & 54 & 53 \\
\hline Day glong & 103 & 103 & 104 & 103 & 101 & 105 & 102 & 100 & 103 & 103 & 102 & 102 \\
\hline Dung dich ol isn & 73 & 74 & 74 & 74 & 74 & 74 & 74 & 74 & 74 & 75 & 75 & 75 \\
\hline \multirow[t]{2}{*}{ Dung dich vao bẻ } & 57 & 58 & 57 & 57 & 57 & 58 & 57 & 56 & 57 & 58 & 59 & 58 \\
\hline & Dnilling & Drilling & Drilling & Drilling & Reaming & Drilling & Drilling & Reaming & Dolling & Drilling & Drilling & Drillins \\
\hline
\end{tabular}

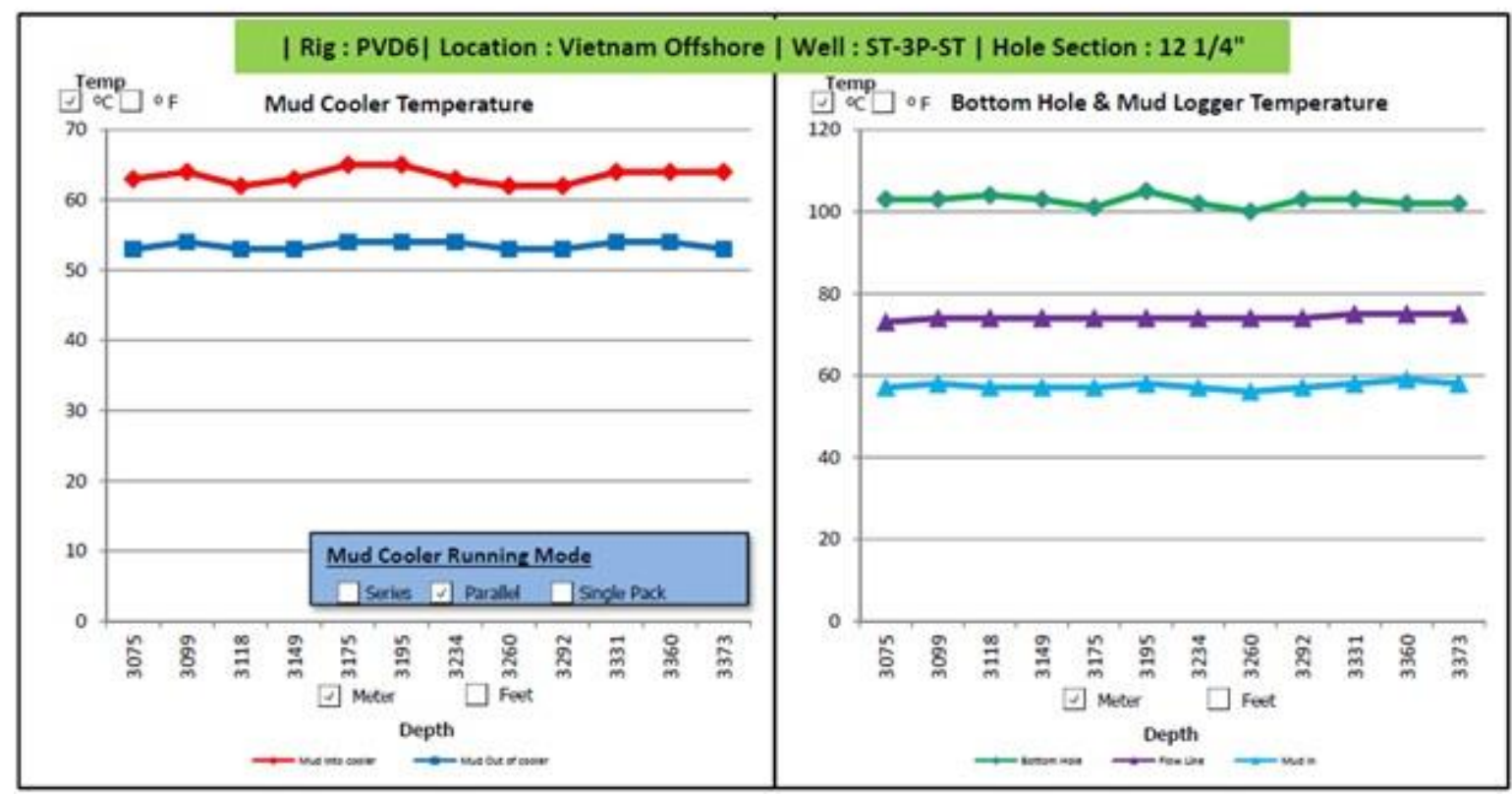

Bảng 2. Các chi phí tiết kiệm do úng dụng hệ thống làm mát dung dịch "Mud cooler" tại giếng khoan ST-3P-ST.

\begin{tabular}{|l|l|r|r|r|}
\hline STT & \multicolumn{1}{|c|}{ Mô Tả } & $\begin{array}{c}\text { Đơn giá } \\
\text { (USD) }\end{array}$ & $\begin{array}{c}\text { Số } \\
\text { lượng }\end{array}$ & $\begin{array}{c}\text { Tổng giá thành } \\
\text { (USD) }\end{array}$ \\
\hline 1 & $\begin{array}{l}\text { Tiết kiệm một lần kéo thả để thay thế bộ khoan cụ BHA, tiết } \\
\text { kiệm được 2 ngày giàn khoan làm việc }\end{array}$ & 55.000 & 2 & 110.000 \\
\hline 2 & Tiết kiệm 2 ngày thuê tàu dịch vụ & 20.000 & 2 & 40.000 \\
\hline 3 & Tiết kiệm 2 ngày thuê dịch vụ khoan của nhà dịch vụ thứ 3 & 175.000 & 2 & 350.000 \\
\hline 4 & $\begin{array}{l}\text { Giảm lượng hóa chất phụ gia để xử lý dung dịch trong môi } \\
\text { trường nhiệt độ cao. }\end{array}$ & 90.000 & 1 & 90.000 \\
\hline 5 & Trừ đi chi phí dịch vụ Mud Cooler & -110.000 & 1 & -110.000 \\
\hline \multicolumn{2}{|l|}{ Tổng cộng: }
\end{tabular}

Với tổng tiết kiệm gần nửa triệu đô la Mỹ (480.000 USD) là một con số rất ấn tượng với ứng dụng thiết bị làm mát "Mud cooler" cho giếng khoan nhiệt độ và áp suất cao. Với việc giảm thời gian kéo thả do bộ khoan cụ bị hỏng, sẽ tăng thời gian khoan; giảm các hiện tượng phức tạp do dung dịch khoan gây ra.

\section{Kết luận}

Ứng dụng hiệu quả thiết bị "Mud cooler" đã giảm thiểu chi phí khoan rất lớn bởi các yếu tố: tăng thời gian làm việc của bộ dụng cụ khoan trong giếng do giảm số lần kéo thả để thay thế dụng cụ phá hủy đá, giữ được tính chất dung dịch ổn định (giảm lượng hóa chất phụ gia để xử lý 
dung dịch), làm mát bề mặt tạo môi trường an toàn cho công nhân viên làm việc trên giàn đặc biệt là những người trực tiếp làm việc với dung dịch hàng ngày, hàng giờ, tiết kiệm thời gian khoan, thời gian thuê tàu, thời gian thuê dịch vụ khoan và giảm thiểu chi phí sử dụng chất phụ gia để phục hồi tính chất của dung dịch...

Những kết quả nghiên cứu trong bài báo đã thể hiện tính ưu việt và hiệu quả khi ứng dụng thiết bị làm mát dung dịch cho giếng nhiệt độ và áp suất cao ST-3P-ST.

\section{Lò̀i cảm ơn}

Thông qua bài báo, tác giả xin gửi lời cảm ơn tới ThS. Phạm Thế Thức, Công ty liên doanh điều hành Cửu Long đã cung cấp số liệu chính xác kịp thời; xin chân thành cảm ơn Bộ môn Khoan Khai thác, Khoa Dầu khí, Trường Đại học Mỏ - Địa chất đã giúp đỡ để công trình khoa học hoàn thành đúng tiến độ và chất lượng.

\section{Đóng góp của tác giả}

Tác giả Nguyễn Trần Tuân đã tiến hành nghiên cứu chế độ nhiệt và phân bổ nhiệt trong các giếng đan dày ở bể Cửu Long, từ đó đề xuất giải pháp và phương án lắp đặt thiết bị làm mát dung dịch khoan nhằm gia tăng hiệu quả khoan và giảm thiểu chi phí đầu tư sản xuất. Tác giả Nguyễn Hoàng Sơn phụ trách xử lý số liệu và chỉnh sửa.

\section{Tài liệu tham khảo}

Công ty liên doanh điều hành Cửu Long. (2018). Chương trình khoan ST-3P-ST, 252 tr.

Trần Đình Kiên (2002), Dung dịch khoan và vữa trám. Giáo trình trường Đại học Mỏ - Địa chất. 305 trang. Trương biên, Nguyễn Xuân Thảo, Phạm Thành, Trần Bản và nnk., (2007). Cẩm nang kỹ sư công nghệ khoan các giếng sâu. NXB KHKT. Hà Nội. 352 trang.

Gilles Gabolde, Jean-Paul Nguyen (2014), Drilling Data handbook. Editions Technip. 305 pages. 